\title{
REDUPLIKASI DALAM NOVEL GARIS WAKTU KARYA FIERSA BESARI (KAJIAN MORFOLOGI)
}

\author{
Sinta Prihatiningrum Simatupang ${ }^{1}$, Sumiharti $^{2}$, Uli Wahyuni ${ }^{3}$ \\ Program Studi Pendidikan Bahasa dan Sastra Indonesia, \\ Fakultas Keguruan dan Ilmu Pendidikan, Universitas Batanghari, \\ Jambi \\ sintaprihati@gmail.com \\ harti.sumi6565@gmail.com \\ uli09yumna@gmail.com
}

\begin{abstract}
The purpose of this research is to describe the reduplication in the aspect of form and meaning in the novel Garis Waktu by Fiersa Besari. This research is a qualitative descriptive. The data are in the form of expressions found in the novel Garis Waktu by Fiersa Besari. Based on the data analysis, thera are 190 expressions of reduplication are found. In the aspect of reduplication, 158 citations were found, with the following details; 1) the most dominant form of reduplication found was whole repetition that was 110 expressions; The dominant form of reduplication is the repetition of affixes that was 34 expressions; the least repetition form were 23 expressions, namely partial repetition; and the form of repetition of phoneme changes found in 3 expressions. As for the aspect of the meaning of reduplication, 32 expressions were found, with the following details: the most dominant meaning of reduplication is seven expressions that was "expressing intensity"; The meaning of reduplication which is quite dominant consists of three parts, namely: 6 expressions for restatement containing the meaning of 'much', 6 expressions for restatement containing words "kinds of", and 6 expressions of rephrasing which contain the meaning of "weakening the meaning'; and the meaning of reduplication was at least 4 repeated expressions with the meaning of "mutually", then 3 repeated expressionswith the meaning of "which resembles the repeated word".
\end{abstract}

Keywords: reduplication, novel Garis Waktu, morphology

\footnotetext{
${ }^{1}$ Mahasiswa Program Studi Pendidikan Bahasa dan Sastra Indonesia, Fakultas Keguruan dan Ilmu Pendidikan, Universitas Batanghari, Jambi

${ }^{2}$ Dosen Program Studi Pendidikan Bahasa dan Sastra Indonesia, Fakultas Keguruan dan Ilmu Pendidikan, Universitas Batanghari, Jambi

${ }^{3}$ Dosen Program Studi Pendidikan Bahasa dan Sastra Indonesia, Fakultas Keguruan dan Ilmu Pendidikan, Universitas Batanghari, Jambi
} 


\section{LATAR BELAKANG}

Bahasa memiliki fungsi dan peran yang sangat penting bagi kehidupan manusia, terutama dalam berkomunikasi dan berinteraksi sesama manusia. Menurut Rahima dan Juanda (2019:1) bahasa adalah alat komunikasi yang sistematis dan terlengkap untuk menyampaikan gagasan dan perasaan. Oleh karena itu, sebagai alat komunikasi bahasa dapat digunakan dalam berbagai lingkungan, situasi dan berbagai kepentingan. Rofii dan Hasibuan (2019:17) mengatakan bahwa Fungsi bahasa yang paling mendasar ialah sebagai alat komunikasi. Bahasa berfungsi sebagai alat untuk menyampaikan ide-ide, gagasan, pengetahuan, dan pikiran manusia.

Komunikasi akan berjalan dengan lancar apabila bahasa yang digunakan tepat sasaran. Artinya bahasa itu dipergunakan sesuai dengan konteks tuturannya, penggunaan bahasa sebagai alat komunikasi bertujuan agar dalam penyampaian gagasan dapat dilakukan secara efesien dan efektif. Terlebih lagi dalam dunia pendidikan, dalam bidang pendidikan dan pengajaran di sekolah, bahasa Indonesia merupakan mata pelajaran wajib.

Tujuan pembelajaran bahasa Indonesia di sekolah, agar siswa mampu dan terampil dalam berbahasa dengan baik dan benar setelah mengalami proses belajar mengajar. Keterampilan berbahasa terdiri atas keterampilan membaca, menulis, mendengarkan (menyimak) dan berbicara. Dalam proses pemerolehan dan penggunaannya, keterampilan berbahasa tersebut saling berkaitan (tidak terpisah satu sama lain). Banyak kajian mengenai bahasa ini, salah satunya kajian tentang morfologi.

$$
\text { Morfologi penting dalam }
$$
pembelajaran bahasa Indonesia, karena di dalam morfologi dipelajari proses norfologis. Hal tersebut senada dengan pendapat Rofii dan Franscy (2018) students are expected to master the process of morphology well. This is because in the process of morphology, the process of word formation, word forming tools, classification of words, meanings of words, as well as changes in the sound produced by the morphological process are described. (Mahasiswa diharapkan menguasai proses morfologi dengan baik. Hal ini karena dalam proses morfologi, dipelajari proses pembentukan kata, alat pembentuk kata, klasifikasi kata, arti kata, serta perubahan suara yang dihasilkan oleh proses morfologi tersebut).

Salah satu hasil proses morfologis yang sering digunakan dalam komunikasi dan berinteraksi melalui tulisan maupun lisan adalah kata ulang yang dihasilkan melalui proses reduplikasi. Selanjutnya Muslich (2008:48) berpendapat bahwa "Proses pengulangan merupakan peristiwa pembentukan kata dengan jalan mengulang bentuk dasar, baik bervariasi fonem maupun tidak, baik berkombinasi dengan afiks maupun tidak". Reduplikasi merupakan salah satu unsur kebahasaan yang sering digunakan dalam percakapan sehari-hari, maupun dalam karya sastra. Bahasa dan sastra berkaitan sangat erat, sebab bahasa merupakan media untuk penyampaian karya sastra.

Suatu bentuk komunikasi yang disampaikan dengan cara yang khas dengan memberikan kebebasan kepada pengarang untuk menuangkan kreativitas imajinasinya berupa ungkapan pikiran dan perasaan, baik tentang kisah maupun kehidupan sehari-hari termasuk bagian karya sastra. Hal ini menyebabkan karya sastra menjadi kompleks sehingga memiliki berbagai kemungkinan penafsiran dalam memahami karya sastra tersebut. Nurgiyantoro (2000: 3) menyatakan bahwa "Karya imajiner, fiksi, 
menawarkan berbagai permasalahan manusia dan kemanusiaan, hidup dan kehidupan". Pengarang menghayati berbagai permasalahan tersebut dengan penuh kesungguhan yang kemudian diungkapkan kembali melalui sarana fiksi sesuai dengan pandangannya.

Novel sebagai salah satu bentuk karya sastra berbentuk prosa yang mempunyai unsur intrinsik dan ekstrinsik yang keduanya saling berhubungan. Novel juga sebagai salah satu bentuk karya sastra selalu menceritakan kehidupan manusia, menggambarkan jalinan peristiwa tentang kehidupan manusia ddan mampu memberi renungan tentang makna dan hakikat kehidupan. Novel selalu menghadirkan rasa ingin tahu pembaca mengenai bahasanya.

Berdasarkan latar belakang yang telah dipaparkan, ada beberapa alasan yang mendasari penelitian tentang reduplikasi yang ada di dalam novel dari Garis Waktu karya Fiersa Besari ini dilakukan. Alasan pertama karena bahasa merupakan komponen terpenting dalam kehidupan manusia. Manusia tidak bisa berinteraksi dengan mudah dan baik jika tidak menguasai. Di era globalisasi saat ini penggunaan bahasa sebagai media komunikasi sangatlah terpengaruh oleh laju perkembangan teknologi dan informasi. Kemudian, alasan kedua, karena di zaman yang sekarang pembaca novel cetak sangat sedikit, masyarakat lebih berminat membaca novel lewat aplikasi yang ada di gawai, media sosial atau di handphone. Inilah alasan mengapa penelitian ini dilakukan, karena diharapkan masyarakat terutama remaja akan mempunyai minat kembali untuk membaca novel.

Novel Garis Waktu ini dipilih sebagai objek penelitian, karena pada novel tersebut terdapat penggunaan reduplikasi yang tidak sesuai penempatan atau hanya sebagai bahan pelengkap dalam kalimat saja. Penelitian ini memfokuskan pada bentuk dan makna reduplikasi dalam novel Garis Waktu karya Fiersa Besari, mulai dari aspek bentuk dasar reduplikasi hingga makna dari setiap reduplikasi tersebut.

\section{METODE PENELITIAN}

Jenis penelitian ini merupakan penelitian deskriptif kualitatif yang berkaitan dengan kajian bahasa pada objek karya sastra. Dalam hal ini pendekatan kualitatif merupakan "Suatu metode penelitian yang diharapkan dapat menghasilkan suatu deskripsi ucapan, tulisan, atau perilaku yang dapat diamati dari suatu individu, kelompok, masyarakat dan/atau organisasi tertentu dalam suatu keadaan atau tata cara yang tertentu pula (Martha, 2016:2). Jenis penelitian kualitatif merupakan cara yang digunakan dalam penelitian untuk mendeskripsikan data-data berdasarkan fakta yang ada. "Penelitian kualitatif dilakukan dengan tidak mengutamakan pada angka-angka tetapi mengutamakan ke dalam penghayatan terhadap interaksi antara konsep yang sedang dikaji secara empiris (Semi, 2012: 23)".

Selanjutnya, Paton (dalam Ahmadi, 2016:15) mengatakan bahwa "Kualitatif adalah memahami fenomena yang sedang terjadi secara ilmiah (natural) dalam keadaan memahami fenomena yang sedang terjadi secara alamiah." Penelitian kualitatif menghasilkan data deskriptif berupa kata-kata.

Teknik pengumpulan data yang digunakan dalam penelitian ini adalah analisis dokumen. Analisis dokumen ini dilakukan untuk mengumpulkan data yang bersumber dari arsip dan dokumen yang ada hubungannya dengan penelitian. "Teknik pengumpulan data merupakan langkah yang paling utama dalam penelitiaan, karena tujuan utama dari 
penelitian adalah mendapatkan data (Sugiyono, 2015: 308)"'.

Analisis data adalah "Proses mencari dan menyusun data yang diperoleh secara sistematis, menjabarkan, menyusun ke dalam pola, memilih mana yang penting dan yang akan dipelajari, serta membuat simpulan agar mudah dipahami oleh diri sendiri maupun orang lain (Sugiyono, 2015:335)". Setelah data dikumpulkan dan dikelompokkan, dari novel Garis Waktu karya Fiersa Besari, selanjutnya dilakukan analisis data.

\section{HASIL DAN PEMBAHASAN}

Berdasarkan hasil penelitian yang telah dilakukan, ditemukan reduplikasi sebanyak 190 kutipan yang terdiri atas bentuk dan makna reduplikasi. pada aspek bentuk reduplikasi diperoleh data sebagai berikut. Bentuk reduplikasi pengulangan seluruh ditemukan sebanyak 110 kutipan. Bentuk reduplikasi pengulangan pembubuhan afiks sebanyak 34 kutipan. Bentuk reduplikasi pengulangan sebagian ditemukan 20 kutipan, dan bentuk reduplikasi pengulangan perubahan fonem 3 kutipan

Pada aspek makna reduplikasi, diperoleh hasil sebagai berikut. Makna reduplikasi yang 'menyatakan intensitas' ditemukan sebanyak 7 kutipan,. Makna reduplikasi yang 'menyatakan banyak' ditemukan sebanyak 6 kutipan. Makna reduplikasi yang 'menyatakan bermacammacam' ditemukan sebanyak 6 kutipan. Makna reduplikasi yang mengandung makna 'melemahkan' ditemukan sebanyak 6 kutipan. Makna reduplikasi yang mengandung makna 'saling' ditemukan sebanyak 3 kutipan dan makna reduplikasi yang 'menyerupai kata yang diulang' sebanyak 3 kutipan.

Penelitan ini membahas tentang penggunaan reduplikasi dalam novel Garis Waktu karya Fiersa Besari. Pembahasan analisis ini mengenai, bentuk reduplikasi yang terdiri dari bentuk yaitu: pengulangan seluruh, pengulangan sebagian, pengulangan yang berkombinasi dengan proses pembubuhan afiks dan pengulangan dengan perubahan fonem. Serta makna kata ulang yang mengandung makna 'banyak yang jumlahya tidak tentu', kata ulang yang bermakna 'bermacam-macam', kata ulang dengan makna 'menyerupai kata yang diulang', kata ulang yang mengandung 'melemahkan arti (agak)', kata ulang yang menyatakan 'intensitas atau kualitas dan kuantitas', dan kata ulang dengan makna 'saling atau pekerjaan yang berbalasan (resiprok)'.

\section{Bentuk Reduplikasi}

Menurut Ramlan (2009) terdapat bentuk pengulangan seluruh, pengulangan sebagian, bentuk pengulangan yang berkombinasi dengan pembubuhan afiksasi, bentuk pengulangan dengan perubahan fonem.

\section{a. Bentuk Pengulangan Seluruh}

Menurut Ramlan (1985:69) pengulangan seluruh ialah pengulangan seluruh bentuk dasar, tanpa perubahan fonem dan tidak berkombinasi dengan proses pembubuhan afiksasi.

Kutipan 1

Karena itulah, meskipun hanya mengangkat hal-hal sederhana, menulis sudah menjadi kebutuhan bagiku (FB.GW.2019:1).

Pada kutipan 1 terdapat kata ulang "hal-hal". Kata ulang tersebut merupakan kata ulang dengan bentuk pengulangan seluruh dari kata dasar "hal" menjadi "hal-hal".

\section{b. Bentuk Pengulangan Sebagian}

Menurut Ramlan (1985:69) pengulangan sebagian adalah pengulangan sebagian dari bentuk dasarnya, dengan kata lain bentuk dasar tidak diulang seluruhnya. Hampir semua bentuk dasar 
pengulangan golongan ini berupa bentuk kompleks.

\section{Kutipan 2}

Di saat yang sama 'Garis Waktu' juga mewakili prosesku menulis di dunia maya selama bertahun-tahun sampai akhirnya membuahkan buku (FB.GW.2019:3)

Pada kutipan 2 terdapat kata ulang "bertahun-tahun" yang merupakan kata ulang dengan bentuk pengulangan sebagian dari kata dasar "tahun" sehingga menjadi "bertahun-tahun". Hal tersebut senada dengan pendapat Chaer (2006: 286) kata ulang ini juga merupakan kata ulang sebagian, karena perulangannya hanya terjadi pada suku kata awalnya saja dan disertai imbuhan.

\section{c. Bentuk Pengulangan yang Berkombinasi dengan Pembubuhan Afiksasi}

Menurut Ramlan pengulangan yang berkombinasi dengan pembubuhan afikasasi, maksudnya pengulangan itu terjadi bersama-sama dengan proses pembubuhan afiks dan bersama-sama pula mendukung satu fungsi.

Kutipan 3

Sebenar-benarnya cemburu yang paling menyakitkan adalah cemburu pada seseorang yang tidak peduli akan perasaan kita (FB.GW.2019:32).

Pada kutipan 3 tersebut terdapat kata ulang "sebenar-benarnya", yang merupakan kata ulang dengan bentuk pengulangan pembubuhan afiks, dari kata dasar "benar-benar" mendapat imbuhan berupa simulfiks se-nya pada kata pertama se- dan kedua -nya sehingga menjadi "sebenar-benarnya".

\section{d. Bentuk Pengulangan dengan Perubahan Fonem}

Menurut Ramlan (1985:69) pengulangan dengan perubahan fonem, yaitu pengulangan bentuk dasar yang disertai perubahan fonem. Kata ulang ini termasuk golongan yang sangat sedikit ditemukan.

Kutipan 4

Kau menjadi seseorang yang memorakmorandakan jagat rayaku (FB.GW.2019:8).

Pada kutipan data tersebut terdapat kata ulang "memorak-morandakan", yang merupakan kata ulang dengan bentuk pengulangan perubahan fonem dalam pengulangan katanya. Huruf $k$ pada kata pertama morak berubah menjadi huruf $n$ pada kata kedua moran sehingga terjadi perubahan bunyi menjadi "memorakmorandakan".

\section{Makna Reduplikasi}

\section{a. Kata Ulang yang Mengandung Makna Banyak}

Kutipan 5

Menaruh harapan padamu seakan menggenggam duri-duri di batang mawar (FB.GW.2019:15).

Pada kutipan 5 tersebut terdapat kata ulang "duri-duri" berdasarkan teori Keraf (1984: 121), yang merupakan kata ulang yang mengandung makna banyak. Makna kata ulang tersebut akan berbeda dengan bentuk "tiga duri", karena "tiga" mempunyai jumlah yang pasti. Jadi duriduri merupakan kata ulang yang mengandung makna banyak duri.

\section{b. Kata Ulang yang Bermakna Bermacam-macam}

Kutipan 6

Celakanya, karena aku menganggap tulisan-tulisan itu hanyalah curahan hati, yang keluar begiru saja secara spontan, (FB.GW.2019:1)

Pada kutipan data tersebut terdapat kata ulang "tulisan-tulisan" berdasarkan teori Keraf (1984: 121), yang merupakan 
kata ulang yang mengandung makna bermacam-macam. Jadi tulisan-tulisan merupakan kata ulang yang bermakna bermacam-macam tulisan atau biasa disebut aneka ragam.

\section{c. Kata Ulang yang Makna Menyerupai Kata yang Diulang}

Kutipan 7

Yang diperebutkan adalah mobil-mobilan, bukan pacar orang lain

(FB.GW.2019:169)

Pada kutipan data tersebut terdapat kata ulang "mobil-mobilan" berdasarkan teori Keraf (1984: 121). Kata ulang tersebut memiliki makna mainan mobil, ciri khusus dari kata ulang menyerupai makna yang diulang ini adalah kata benda yang memiliki proses afiksasi yaitu sufiks $-a n$.

\section{d. Kata Ulang yang Mengandung Melemahkan Arti}

Kutipan 8

Karena sahabat bukanlah orang yang bermanis-manis di depan kita (FB.GW.2019:190).

Pada kutipan tersebut terdapat kata ulang "bermanis-manis" berdasarkan teori Keraf (1984: 121). Kata ulang tersebut mengandung makna 'melemahkan arti' karena hal ini biasa juga disebut dengan kata agak. Jadi, kata ulang bermanis-manis bermakna yaitu agak manja ataupun berlebihan dalam bersikap.

\section{e. Kata Ulang yang Menyatakan Intensitas}

Kutipan 8

Tak perlu repot-repot menyamakan diri dengan orang lain, kau diciptakan untuk menjadi unik (FB.GW.2019:28).

Pada kutipan tersebut terdapat kata ulang "repot-repot" berdasarkan teori Keraf (1984: 121). Kata ulang ini memiliki makna sesuatu yang dilakukan dengan intensitas yang banyak kerja.

\section{f. Kata Ulang dengan Makna Saling atau Pekerjaan yang Berbalasan}

Kutipan 9

Kita sama-sama pejuang

(FB.GW.2019:60)

Pada kutipan tersebut terdapat kata

ulang "sama-sama" berdasarkan teori Keraf (1984: 121). Kata ulang ini memiliki makna saling atau pekerjaan yang berbalasan, jadi kata ulang sama-sama bermakna terdapat kedua pihak yang saling memperjuangkan cintanya.

\section{SIMPULAN}

Berdasarkan hasil dan pembahasan maka dapat disimpulkan sebagai berikut. Terdapat reduplikasi sebanyak 190 kutipan yang terdiri atas bentuk dan makna reduplikasi.

1. Dalam novel Garis Waktu karya Fiersa Besari ditemukan bentuk reduplikasi sebanyak 158 kutipan, sebagai berikut: bentuk reduplikasi yang paling dominan yaitu bentuk pengulangan seluruh ditemukan sebanyak 110 kutipan, bentuk reduplikasi pengulangan pembubuhan afiks ditemukan 34 tiga kutipan; bentuk pengulangan sebagian ditemukan 20 kutipan dan ditemukan tiga kutipan bentuk pengulangan perubahan fonem.

2. Dalam novel Garis Waktu karya Fiersa Besari ditemukan makna reduplikasi sebanyak 32 kutipan, sebagai berikut: makna reduplikasi yang paling dominan yaitu makna kata ulang yang 'menyatakan intensitas' ditemukan sebanyak 7 kutipan, makna kata ulang yang mengandung makna 'banyak', ditemukan sebanyak 6 kutipan; makna kata ulang yang mengandung makna 'bermacam-macam' ditemukan sebanyak 6 kutipan, makna kata ulang yang mengandung makna "melemahkan arti' ditemukan 
sebanyak 6 kutipan, makna kata ulang dengan makna 'saling' ditemukan sebanyak 4 kutipan, selanjutnya makna kata ulang yang 'menyerupai kata yang diulang' ditemukan sebanyak 3 kutipan.

\section{Saran}

Berdasarkan hasil penelitian penggunaan reduplikasi dalam novel Garis Waktu karya Fiersa Besari, dapat diajukan beberapa saran sebagai berikut.

1. Bagi penulis berikutnya, kiranya untuk melakukan penelitian lebih lanjut yang lebih menyeluruh terkiat reduplikasi secara bentuk serta maknanya.

2. Bagi pembaca, hasil penelitian ini diharapkan dapat digunakan sebagai informasi mengenai penggunaan reduplikasi serta penempatan yang sesuai dengan konteks dalam berkomunikasi lisan maupun tulisan.

\section{DAFTAR PUSTAKA}

Ahmadi, Rulam. (2016). Metode Penelitian Kualitatif. Yogyakarta: Ar-Ruzz Media.

Chaer Abdul. (2015). Morfologi Bahasa Indonesia:Pendekatan Proses. Jakarta: Rineka Cipta.

Keraf, Gorys. (1984). Tata Bahasa Indonesia. Ende: Nusa Indah.

Martha, dkk. (2016). Metodologi Penelitian Kualitatif Untuk Bidang Kesehatan. Jakarta: PT. Grafindo Persada.

Muslich, Masnur. (2008). Tata Bentuk Bahasa Indonesia;Kajian ke Arah Tata Bahasa Deskriptif. Jakarta: Bumi Aksara.

Nurgiyantoro, Burhan. (2000). Teori Pengkajian Fiksi. Yogyakarta: Gadjah Mada Universiti Press.

Rahima. A dan Juwanda. M (2019). Bentuk Nomina Bahasa Melayu Jambi di desa Peninjau, Kecamatan Bathin II Pelayangan, Kabupaten
Muaro Bungo, Provinsi Jambi. (Kajian Morfologi). Aksara: Jurnal Ilmiah Pendidikan Bahasa dan Sastra Indonesia, 3(1), 9-15.

Ramlan, M. (1985). Tata Bahasa Indonesia: Penggolongan Kata. Yogyakarta: Andi Offset.

Ramlan, M. (2009). Morfologi Suatu Tinjauan Deskriptif. Yogyakarta: CV Karyono.

Rofii, Afif. dan Franscy. (2018). The Development of Contextual-Based Texbook on Morphological Process in Faculty of Teachers Training and Education Batanghari University Jambi. The Asian ESP Journal. Volume 14 Issue 2 Juli 2018. ISSN 2206-0979.

Rofii, Afif. dan Hasibuan, Rizka Rani (2019) Interferensi Bahasa Batak Mandailing dalam Tuturan Berbahasa Indonesia Pada Acara Parpunguan Masyarakat Mandailing Kota Jambi. Aksara. Aksara: Jurnal Ilmiah Pendidikan Bahasa dan Sastra Indonesia Vol. 3 No. 1 April 2019.

Sugiyono. (2007). Metode Penelitian Kuantitaif, Kualitatif, dan $R \& D$. Bandung: Alfabeta. 